\title{
Effect of different modes of pollination on quantitative and qualitative parameters of Egyptian Clover, Trifolium alexandrinum $\mathrm{L}$.
}

\author{
M. K. Jat, O. P. Chaudhary, H. D. Kaushik, Sunita Yadav* and A. S . Tetarwal
}

Department of Entomology, College of Agriculture, CCS Haryana Agricultural University, Hisar-125004 (Haryana), INDIA

*Corresponding author. E-mail: sunitayadav10@rediffmail.com

Received: July 11, 2014; Revised received: September 05, 2014; Accepted: November 05, 2014

Abstract: The effect of different modes of pollination on quantitative and qualitative parameters of Egyptian clover, Trifolium alexandrinum L. was studied at Forage Section, Department of Genetics and Plant Breeding, CCS, Haryana Agricultural University, Hisar during 2012 and 2013. Maximum seed setting (81.5\%) was recorded in A. mellifera pollination with an 8 frame colony (BP-8F) followed by 4 frame colony (BP-4F) $(75.1 \%)$, open pollination (OP) $(73.8 \%)$ and 2 frame colony (BP-2F) (71.5\%). Maximum seed yield (2662.3 seeds) was observed in treatment BP-8F followed by BP-4F (2373.8), OP (2316.3) and BP-2F (2235.5). Still lower yield of 2103.0 seeds was found in hand pollination (HP) treatment that was significantly higher than the without insect pollination (WIP) treatment (1114.2). Minimum 1000-seed weight was observed in WIP $(2.64 \mathrm{~g})$. The seed weight of BP-4F (3.30), HP (3.20), BP-2F (3.17) and OP (3.03), the heaviest seeds were recorded in BP-8F (3.62 g/1000 grains) and it was at par with the treatment BP-4F $(3.30 \mathrm{~g})$. Highest seed germination per cent was recorded in BP-8F (94.7) followed by OP $(90.7 \%)$. Lowest germination was found in WIP (84.7\%). Though some work has been done on this aspect in India but comprehensive pollination studies has not been worked out.

Keywords: Bee Pollination, Egyptian clover, Germination per cent, Seed setting, Seed weight

\section{INTRODUCTION}

Egyptian clover, Trifolium alexandrinum L. commonly called berseem (Family Leguminaceae, sub-family Papilionaceae), owing to higher quantitative yield parameters viz., green fodder yield (85 t/ha) and multi-cut nature (4-6 cuts) along with qualitative parameters namely, succulency, high palatability, nutritive value ( $20 \%$ crude protein), digestibility (up to $65 \%$ ) and continuous supply of over seven months (November to May). Egyptian clover is one of the most entomophilic crop requiring insects, especially bees for cross pollination. Singh et al. (2012) also reported higher per plot $\left(18 \mathrm{~m}^{2}\right)$ seed yield in plots caged with Apis mellifera colony (4-frame) as compared to plots caged without insect pollination. Honey bees are reported to be the primary and absolutely essential pollinators of Egyptian clover, visiting it avidly for nectar and pollen and significantly increasing seed yield. According to Sharma and Singh, (2003) A. dorsata ( 6.55 bees) was the most abundant floral visitor followed by A. mellifera (4.4 bees) and A. florea (1.52). Seed yield in open pollinated plants ranged from 19.6-70.5 seeds per flower head compared to only 0.3-0.6 seeds where insects were excluded (caged). With immense scope to increase production of biomass and seeds of $T$. alexandrinum, a variety of pollinators has been used by the man for guided pollination or "planned pollination" that included $A$. mellifera, A. cerana, Osmia cornuta and O. rufa (Pinzauti and Martiniello, 2003).

The aim of present study was to determine the effect of different modes of pollination on quantitative and qualitative yield parameters of T. alexandrinum and to find out colony strength (frames/colony), of $A$. mellifera required for enhancing different parameters of $T$. alexandrinum seed yield.

\section{MATERIALS AND METHODS}

Effect of modes of pollination on quantitative and qualitative yield parameters: The effect of different modes of pollination (MOP) on T. alexandrinum yield (both quantitative and qualitative) was investigated using following four modes:

$\mathbf{T}_{1}$ - Without insect pollination (WIP): In WIP or caged without bees (CWB), the plants in the plot were caged in a nylon net $(6 \times 4 \times 3 \mathrm{~m})$ of $16 \mathrm{~mm}$ mesh size as explained below in bee pollination. The crop was sprayed with chlorpyriphos 20 EC to kill all the insects inside the cage to prevent their contribution towards pollination. However, in WIP, no honey bee colony was placed inside. The net prevented pollination by any insect or other pollinators.

$\mathbf{T}_{2}$ - Open pollination (OP): These plots were not caged and remained exposed/open for access to pollination by all agencies at all times. 
$\mathbf{T}_{3}$ - Hand pollination (HP): In the HP plots, 50 flower buds of $T$. alexandrinum were selected randomly and tagged. They were enclosed in nylon net bags before opening to avoid pollination. As these flowers opened and become receptive, they were pollinated by hand and further enclosed. The pollen was collected from ripe flowers that were shaken to drop pollen grains into a Petri plate. With the help of a soft camel hair brush, the collected pollen grains were smeared on the tagged receptive flowers. Hand pollination was performed between 1100 to $1330 \mathrm{~h}$ when the pollen is abundantly available. The net bag was removed after fertilization for the proper development of seed.

$\mathbf{T}_{4}$ to $\mathbf{T}_{6}-$ Bee pollination (BP): The bee pollinated plots were caged in nylon net as explained for WIP. The nets were got stitched using nylon cloth of 16-mesh size sufficient to exclude the entry of insects in the cage but did not hinder other physical factors. Cage height was $3.5 \mathrm{~m}$ sufficient to allow unhindered movement of honey bees inside. These cages were erected with the help of bamboo poles and tightened with the help of cords. The net clothing touching the ground was sufficiently pressed under the soil so as to prevent entry of any insects. A zipped entry was kept at one corner of the net to allow manual entry for data recording and other operations. Care was taken to immediately zip-close the cage after entry/exit. The crop was caged at the beginning of flowering and sprayed with chlorpyriphos $20 \mathrm{EC}$ to kill all the insects inside the cage to exclude their contribution towards pollination. After the waiting period of insecticide, a colony of A. mellifera in standard deep LT wooden hive was kept inside the net just at the start of flowering, not later than 10 percent flowering. The colony strength depended upon the treatments given below. The colony was regularly provided with water. The bee colony was removed when all the tertiary bloom was complete. Based on the colony strength (frames/colony), following three treatments were taken:

$\mathrm{T}_{4}$ (BP-8F)- A. mellifera colony of eight-frame strength

$\mathrm{T}_{5}$ (BP-4F)- A. mellifera colony of four-frame strength $\mathrm{T}_{6}(\mathrm{BP}-2 \mathrm{~F})-$ A. mellifera colony of two-frame strength All these treatments $\left(\mathrm{T}_{4}-\mathrm{T}_{6}\right)$ were replicated thrice in a plot area of $24 \mathrm{~m}^{2}$ and plot $\mathrm{T}_{1}, \mathrm{~T}_{4}, \mathrm{~T}_{5}$ and $\mathrm{T}_{6}$ had a volume of $84 \mathrm{~m}^{2}$.

Recording of observations: Fifty flower heads or racemes were randomly selected and tagged in each replication $(n=3)$ of different treatments. At maturity, they were manually harvested. The following quantitative and qualitative yield parameters were recorded from these racemes:

Number of florets per raceme: After harvesting, twenty flower heads (racemes) were randomly selected from each replication of the treatment. Number of florets per raceme were counted and their mean was calculated.

Number of seeds per raceme: After counting the number of florets from above selected racemes, number of seeds per raceme was also counted and mean seed number was determined.

Seeds setting (\%): From randomly selected and marked 20 racemes, number of florets per raceme was counted. At harvesting, number of seeds per raceme was counted. Seed setting per cent was calculated by: Seed setting $(\%)=$ No. of seeds per raceme $/$ No. of florets per raceme raceme $\mathrm{X} 100$

Number of seeds (seed yield): Total number of seeds obtained from the thrashing of 50 racemes was counted with the help of seed counter (Numigral).

1000-seed weight: Thousand seeds from each replication of individual treatments thus counted were weighed with the help of electronic weighting machine (FCOSCT) to get 1000-seed weight in grams.

Seed germination (\%): For recording seed germination, fifty seeds constituted one replication and three replications for each treatment were taken. These seeds were kept on the wet circular filter paper placed in a Petri dish $(15 \mathrm{~cm})$ and covered. This Petri dish was kept in a germinator, maintained at a temperature of $21 \pm 1^{0} \mathrm{C}$ and $\mathrm{RH}$ of 75 per cent for 6 days after which the seed germination was recorded and expressed in percentage.

All the data pertaining to number of seeds, seed weight and germination per cent were statistically analyzed by using factorial arrangement in randomized block design.

\section{RESULTS AND DISCUSSION}

Effect of different modes of pollination on quantitative and qualitative yield parameters: For evaluating the effect of different modes on pollination on quantitative and qualitative yield parameters, six treatments were undertaken including three bee pollination (BP) viz. caging with a 8-frame $A$. mellifera colony (T-4, BP-8F); caging with a 4-frame A. mellifera colony (T-5, BP-4F); caging with a 2-frame A. mellifera colony (T-6, BP-2F); that were compared with open pollination (T-2, OP) where crop was uncaged and had free access to floral visitors; hand pollination (T-3, HP) and caged to avoid contact with any floral visitors called without insect pollination (T-1, WIP).

Effect of different modes of pollination on seed setting of T. alexandrinum: A T. alexandrinum flower head on an average contained of 66.9-68.3 florets (Table 1). The treatment where crop was caged to avoid any contact with floral visitors (WIP) resulted in minimum seed set of 23.4 seeds/floret while hand pollination increased it significantly to 43.3 seeds. Seed setting in BP-2F, open pollination and BP-4F though still increased (48.6, 51.1 and 51.2 seeds/floret, respectively) but this increase was the most (56.4/ floret) in plots where bee pollination with an 8 -frame 
Table 2. Effect of different modes of pollination on the number of T. alexandrinum seeds.

\begin{tabular}{|c|c|c|c|c|c|c|c|c|c|c|}
\hline \multirow{3}{*}{ Modes of pollination } & \multicolumn{8}{|c|}{ Mean number of seeds/ 50 flowers in different years } & \multirow{3}{*}{$\begin{array}{c}\text { Over } \\
\text { all } \\
\text { mean }\end{array}$} & \multirow{3}{*}{$\begin{array}{c}\text { Increase } \\
\text { over } \\
\text { WIP } \\
(\%)\end{array}$} \\
\hline & \multicolumn{4}{|c|}{2012} & \multicolumn{4}{|c|}{2013} & & \\
\hline & $\mathbf{R}_{1}$ & $\mathbf{R}_{\mathbf{2}}$ & $\mathbf{R}_{3}$ & Mean & $\mathbf{R}_{\mathbf{1}}$ & $\mathbf{R}_{\mathbf{2}}$ & $\mathbf{R}_{\mathbf{3}}$ & Mean & & \\
\hline $\begin{array}{l}\text { Without insect } \\
\text { pollination (WIP) }\end{array}$ & $\begin{array}{l}1046.0 \\
*\end{array}$ & 1223.0 & 1036.0 & 1101.7 & 1190.0 & 1080.0 & 1110.0 & 1126.7 & 1114.2 & - \\
\hline Open pollination - OP & 2452.0 & 2276.0 & 2016.0 & 2248.0 & 2594.0 & 2390.0 & 2170.0 & 2384.7 & 2316.3 & 207.9 \\
\hline Hand pollination - HP & 1817.0 & 2213.0 & 2003.0 & 2011.0 & 2010.0 & 2292.0 & 2283.0 & 2195.0 & 2103.0 & 188.7 \\
\hline Bee pollination- $\mathrm{BP}-8 \mathrm{~F}$ & 2552.0 & 2493.0 & 3000.0 & 2681.7 & 2630.0 & 2689.0 & 2610.0 & 2643.0 & 2662.3 & 238.9 \\
\hline Bee pollination - $\mathrm{BP}-4 \mathrm{~F}$ & 2378.0 & 2195.0 & 2438.0 & 2337.0 & 2390.0 & 2489.0 & 2353.0 & 2410.7 & 2373.8 & 213.0 \\
\hline Bee pollination- $\mathrm{BP}-2 \mathrm{~F}$ & 2054.0 & 2298.0 & 2135.0 & 2162.3 & 2280.0 & 2294.0 & 2352.0 & 2308.7 & 2235.5 & 200.6 \\
\hline Mean & 2049.8 & 2116.3 & 2104.7 & & 2182.3 & 2182.3 & 2205.7 & & & \\
\hline $\mathrm{CD}(\mathrm{p} \leq 0.05)$ & & & & 367.8 & & & & 228.1 & 185.9 & \\
\hline $\mathrm{SE}(\mathrm{m})$ & & & & 115.2 & & & & 71.5 & 63.3 & \\
\hline
\end{tabular}

*Values are the mean of 50 observations

Table 3. Effect of different modes of pollination on 1000-seed weight of T. alexandrinum.

\begin{tabular}{|c|c|c|c|c|c|c|c|c|c|c|}
\hline \multirow{3}{*}{ Modes of pollination } & \multicolumn{8}{|c|}{ 1000- seed weight in different years (g) } & \multirow{3}{*}{$\begin{array}{l}\text { Overall } \\
\text { mean }\end{array}$} & \multirow{3}{*}{$\begin{array}{c}\text { Increase } \\
\text { over } \\
\text { WIP } \\
(\%) \\
\end{array}$} \\
\hline & \multicolumn{4}{|c|}{2012} & \multicolumn{4}{|c|}{2013} & & \\
\hline & $\mathbf{R}_{1}$ & $\mathbf{R}_{\mathbf{2}}$ & $\mathbf{R}_{\mathbf{3}}$ & Mean & $\mathbf{R}_{1}$ & $\mathbf{R}_{\mathbf{2}}$ & $\mathbf{R}_{\mathbf{3}}$ & Mean & & \\
\hline $\begin{array}{l}\text { Without insect } \\
\text { pollination (WIP) }\end{array}$ & $2.61 *$ & 2.82 & 2.70 & 2.71 & 2.27 & 2.81 & 2.61 & 2.56 & 2.64 & - \\
\hline Open pollination - OP & 2.71 & 3.02 & 2.99 & 2.90 & 3.47 & 2.99 & 3.01 & 3.16 & 3.03 & 114.77 \\
\hline Hand pollination $-\mathrm{HP}$ & 3.08 & 3.19 & 3.08 & 3.12 & 3.39 & 3.33 & 3.11 & 3.27 & 3.20 & 121.21 \\
\hline Bee pollination- $\mathrm{BP}-8 \mathrm{~F}$ & 3.78 & 3.38 & 3.10 & 3.42 & 3.89 & 4.48 & 3.10 & 3.82 & 3.62 & 137.12 \\
\hline Bee pollination $-\mathrm{BP}-4 \mathrm{~F}$ & 3.49 & 3.34 & 3.28 & 3.37 & 3.20 & 3.29 & 3.32 & 3.28 & 3.30 & 125.00 \\
\hline Bee pollination- $\mathrm{BP}-2 \mathrm{~F}$ & 3.20 & 3.29 & 3.09 & 3.19 & 3.09 & 3.27 & 3.09 & 3.16 & 3.17 & 120.08 \\
\hline Mean & 3.15 & 3.17 & 3.04 & & 3.22 & 3.36 & 3.04 & & & \\
\hline $\mathrm{CD}(\mathrm{p} \leq 0.05)$ & & & & 0.32 & & & & 0.59 & 0.32 & \\
\hline $\mathrm{SE}(\mathrm{m})$ & & & & 0.01 & & & & 0.18 & 0.11 & \\
\hline
\end{tabular}

*Values are the mean of 50 observations

A. mellifera colony (BP-8F) was done.

The seed setting (\%) was minimum in WIP (34.0\%) and hand pollination significantly increased it further to 61.8 per cent. It still became significantly higher in BP-2F (70.6\%), OP (73.8\%) and BP-4F treatments (75.1\%) but the further additional bee pollination input in plots of BP-8F produced highest seed set of 81.4 per cent. Though hand pollination increased seed set significantly but it was still falling short. The input of bee pollination through managed bee pollination at low intensity (BP-2F), open pollination and medium intensity bee pollination (BP-4F) increased seed setting by 207.6-220.9 per cent over WIP but increasing the honey bee density/unit area further (BP-8F) resulted in an increase of 239.3 per cent over WIP, a further increment of 18.4 per cent in seed setting even over bee pollination at medium intensity level (BP-4F) and 22.4 per cent over open pollination. The present studies thus, clearly indicated that employing honey bee as an agent of pollination and open pollination where honey bees are the major constituent significantly increase seed set but opting for even higher intensity of pollination or "saturated pollination" has the potential to realize maximum seed setting. These findings are amply supported by the work of Chowdhury et al. (1966) who reported significantly higher seed setting in plots where hand tripping and open pollination was employed (42.13 and $44.07 \%)$ compared to selfing $(8.50 \%)$ and Beri et al. (1985) who recorded higher seed setting under open pollination $(53.0 \%)$ compared with WIP $(26.3 \%)$ and pollinators + hand tripping (52\%). Similarly, Roy et al. (2005) found a reduction of 12.3-99.2 per cent in WIP compared to open pollinated condition. Malaviya et al. (1999) also reported 83.5-84.7 per cent decline in diploid and 60.6-78.4 per cent for tetraploid lines in 
Table 4. Effect of different modes of pollination on seed germination of T. alexandrinum

\begin{tabular}{|c|c|c|c|c|c|c|c|c|c|}
\hline \multirow{3}{*}{ Modes of pollination } & \multicolumn{8}{|c|}{ Seed germination in different years $(\%)$} & \multirow{3}{*}{$\begin{array}{c}\text { Overall } \\
\text { mean }\end{array}$} \\
\hline & \multicolumn{4}{|c|}{2012} & \multicolumn{4}{|c|}{2013} & \\
\hline & $\mathbf{R}_{1}$ & $\mathbf{R}_{2}$ & $\mathbf{R}_{\mathbf{3}}$ & Mean & $\mathbf{R}_{1}$ & $\mathbf{R}_{\mathbf{2}}$ & $\mathbf{R}_{\mathbf{3}}$ & Mean & \\
\hline $\begin{array}{l}\text { Without insect pollination } \\
\text { (WIP) }\end{array}$ & $86.0 *$ & 86.0 & 90.0 & $\begin{array}{c}87.3 \\
(69.8)^{*}\end{array}$ & 78.0 & 82.0 & 86.0 & $\begin{array}{c}82.0 \\
(65.0)\end{array}$ & $\begin{array}{c}84.7 \\
(67.1)\end{array}$ \\
\hline Open pollination - OP & 92.0 & 90.0 & 90.0 & $\begin{array}{c}90.7 \\
(72.2)\end{array}$ & 90.0 & 90.0 & 92.0 & $\begin{array}{c}90.7 \\
(72.2)\end{array}$ & $\begin{array}{c}90.7 \\
(72.2)\end{array}$ \\
\hline Hand pollination - HP & 92.0 & 94.0 & 92.0 & $\begin{array}{c}92.7 \\
(74.3)\end{array}$ & 92.0 & 96.0 & 94.0 & $\begin{array}{c}94.0 \\
(75.9)\end{array}$ & $\begin{array}{c}93.3 \\
(75.2)\end{array}$ \\
\hline Bee pollination- $\mathrm{BP}-8 \mathrm{~F}$ & 94.0 & 96.0 & 94.0 & $\begin{array}{c}94.7 \\
(76.7)\end{array}$ & 94.0 & 94.0 & 96.0 & $\begin{array}{c}94.7 \\
(76.7)\end{array}$ & $\begin{array}{c}94.7 \\
(76.3)\end{array}$ \\
\hline Bee pollination - BP-4F & 94.0 & 92.0 & 96.0 & $\begin{array}{c}94.0 \\
(75.9)\end{array}$ & 96.0 & 90.0 & 94.0 & $\begin{array}{c}93.3 \\
(75.3)\end{array}$ & $\begin{array}{c}93.7 \\
(75.6)\end{array}$ \\
\hline Bee pollination- $\mathrm{BP}-2 \mathrm{~F}$ & 96.0 & 94.0 & 92.0 & $\begin{array}{r}94.0 \\
(75.9) \\
\end{array}$ & 94.0 & 94.0 & 90.0 & $\begin{array}{c}92.7 \\
(74.4) \\
\end{array}$ & $\begin{array}{r}93.3 \\
(75.1) \\
\end{array}$ \\
\hline Mean & 92.3 & 92.0 & 92.3 & & 90.7 & 91.0 & 92.0 & & \\
\hline $\mathrm{CD}(\mathrm{p} \leq 0.05)$ & & & & 3.8 & & & & 4.9 & 2.6 \\
\hline $\mathrm{SE}(\mathrm{m})$ & & & & 1.2 & & & & 1.5 & 0.9 \\
\hline
\end{tabular}

*Values in parenthesis are arc sin transformation values

WIP as compared to open pollination. Caging with $A$. florea improved seed set marginally, while caging with A. mellifera recorded lower seed set loss (18.7-37.8\%). Singh et al. (2012) recorded almost similar but higher seed setting under open pollination condition (62.46\%) and bee pollination with 4 -frame A. mellifera colony $(61.01 \%)$ and the lowest $(40.33 \%)$ in without insect pollination.

Similarly, many studies reported higher seed set in bee pollination than open pollination. Hassanein (1953) recorded highest seed setting $(38.9 \%)$ in BP followed by OP $(23.5 \%)$ and minimum in WIP (1.9 seeds/head) and similarly, Bakheit (1989) found highest seed setting in BP with A. mellifera (51.9\%) followed by hand pollination $(17.1 \%)$ and least in caged conditions $(0.96 \%)$. Like in the present studies, many researchers have tried various modes of pollination (Chowdhury et al., 1966; Narayanan et al., 1961; Singh et al., 2012) and accepted the need of honey bees to increase seed yield (McGregor, 1976; Free, 1960). But there is a clear lack of efforts on utilizing various densities of bee populations and that may be the reason of lower seed set recorded by these workers. However, these studies clearly indicate to the highest benefits of saturated pollination where maximum $(81.4 \%)$ seed setting was recorded.

Effect of different modes of pollination on seed yield of $\boldsymbol{T}$. alexandrinum: The quantitative yield produced by $T$. alexandrimum is the ultimate reflection of the symbiotic relationship it had with various floral visitors resulting from the process of pollination and fertilization.

The lowest yield (Table 2) was obviously recorded in plots where insect pollination component was excluded as only 1114.2 seeds/50 flower heads were obtained compared to all other treatments where pollination component was involved. Relatively higher seed yields were obtained in hand pollinated (2103.0) and bee pollination at low intensity (BP-2F) treatments (2235.5 seeds) that was comparable to open pollination (2316.3) and BP-4F. The saturated pollination (BP-8F) gave maximum seeds (2662.3). Incorporation of insect pollination component increased seed yields by a whopping 200.6 to 213.0 per cent over WIP lacking this component but still higher increase of 238.9 per cent was recorded when saturated pollination in $\mathrm{BP}-8 \mathrm{~F}$ was considered. It gave even 25.9 per cent higher yields over medium bee pollination level (BP-4F) and 31.0 per cent over natural pollination in OP. The studies thus, clearly indicated the immense value of bee pollination in achieving higher yield in T. alexandrinum. The previous studies in contrast reported higher seed yields in open pollination (Singh et al., 2012) at $136 \mathrm{~g} / 18 \mathrm{~m}^{2}$ plot followed by plots with a 4-frame A. mellifera colony (130.67 g) and least (60.50 g) in plots caged without insect pollination. Similarly, Narayanan et al. (1961) reported higher (1958 and 2671 seeds/100 flower heads) yields in two plots compared to only 27 to 28 seeds with automatic self pollination in cages during 1957 and also during 1960 at 4360 and 7054 seeds under OP compared to 64 and 43 with WIP. This increase in seed yield was 72-95 times by numbers and 184-319 times by weight during 1957 and during 1960, 68-213 times higher by numbers and 72.5 -141.5 times by weight. The higher yields in present studies could be explained by the employment of the concept of "saturated pollination" where higher intensity of honey bees/unit area was used by keeping an 8 -frame A. mellifera colony as the previous workers only went upto 4 -frame colony. 
The present studies further made it amply clear that even after employing natural pollination (OP) and components of lower and medium honey bee pollination intensities (BP-2F and BP-4F), there still remained immense scope of further pollinating the florets, a fact corroborated by additional higher seed yields in saturated pollination (BP-8F) to the tune of 25.9 per cent compared to OP and 31.0 per cent over medium intensity bee pollination (BP-4F). There is no work reported in literature on these lines.

Effect of different modes of pollination on 1000 seed weight of $\boldsymbol{T}$. alexandrinum: The seed weight is a direct index of the seed health and vigour that eventually determines quantitative (yield) and qualitative parameters (Table 3). A bolder and heavier seed is the result of proper post pollination and fertilization development processes and is supposed to be better than normal or shrivelled seeds especially in a crop like $T$. alexandrinum where seed has no other purpose like food or feed. A bolder seed is an indicator of better germination by providing more food reserve to the germination seedlings. The 1000 -seed weight thus, is an index of basic seed characteristics.

The saturated bee pollination treatment with 8 -frame A. mellifera ensured maximum pollination of available T. alexandrinum florets, thus resulting not only in higher number but also heavier seeds with maximum 1000-seed weight of $3.62 \mathrm{~g}$ and in absence of any pollination input (WIP) lightest seeds with $2.64 \mathrm{~g} / 1000$ seeds were recorded. The seed weight in $\mathrm{BP}-4 \mathrm{~F}$, hand pollination, BP-2F and open pollination treatments though significantly heavier than WIP $(3.30,3.20,3.17$ and $3.03 \mathrm{~g}$, respectively) but were significantly lighter than the BP-8F treatment. The results while signifying the need of insect visitors also show a moderate increase in seed weight by employing different modes of pollination as compared to WIP but there still remained un-pollinated florets and honey bee pollination with higher population densities (BP-8F) filled this gap that resulted in more bold seeded crop with an additional weight of 137.2 per cent over WIP. These results find full support from Free (1993) who also reported higher seed weight/1000 heads in bee pollinated plots (13.8 g) compared to only $0.2 \mathrm{~g}$ in without insect pollination but was significantly lower in open pollination $(6.1 \mathrm{~g})$. However, the findings of Singh et al. (2012) do not support present studies who reported lower 1000-seeds weight $(2.47 \mathrm{~g})$ in plots caged with $A$. mellifera colony compared to open pollinated plot $(2.51 \mathrm{~g})$ and lowest under without insect pollination $(2.22 \mathrm{~g})$.

Effect of different modes of pollination on seed germination of $\boldsymbol{T}$. alexandrinum: The seed germination is the most important indices of the viability of seed (Table 4). It is a solid indicator of the history of processes of pollination, fertilization and subsequent seed development, the success or failure (complete or partially) will ultimately reflect in seed quality and govern the furtherance of the generation of plants (Chaudhary, 1998).

In plots, devoid of any insect pollination activity (WIP), seeds with minimum germination $(84.7 \%)$ were recorded, though this level was well above the minimum germination required for seed standards $(80.0 \%)$. Crop's exposure to open pollination increased it further to 90.7 per cent. The maximum germination however, was recorded in all bee pollination treatments i.e. BP-8F (94.7\%), BP-4F (93.7), BP-2F (93.3) and in hand pollination $(93.3 \%)$ with statistically similar values. Employing these pollination inputs increased seed germination by 7.1-11.8 per cent. Singh et al. (2012) while acknowledging the role of different modes of pollination reported contradictory findings of highest germination from open pollination plots $(90.67 \%)$ followed by plots caged with a 4 -frame $A$. mellifera colony $(88.67 \%)$ and the lowest in without insect pollination plots $(80.00 \%)$.

\section{Conclusion}

This study concluded that the seeds setting (\%), seed yield, 1000 grains seed weight and per cent germination of $T$. alexandrinum significantly increased under bee pollination treatments than compared to other treatments. Saturated bee pollination by employing an 8- frame A. mellifera colony resulted in significantly higher yield over lower intensity bee pollination (4 and 2 frame colonies) and open pollination. The utility of T. alexandrinum crop as highly valuable nectar and pollen sources was confirmed for A. mellifera colony development.

\section{REFERENCES}

Bakheit, B.R. (1989). Pollination and seed setting in different genotypes of Egyptian clover (Trifolium alexandrinum L.). Assiut Journal of Agricultural Sciences, 20(1): 199208.

Beri, S.M., Sohoo, M.S. and Sharma H.L. (1985). Estimates of natural cross pollination in Egyptian clover. Euphytica, 34: 147-151.

Chaudhary, O.P. (1998). Role of insect pollinators in seed production and its quality. In: Seed Quality Assurance, CCS, Haryana Agricultural University, Hisar, pp. 86113.

Chowdhury, J.B., Mehta, R.K. and Joshi, A.B. (1966). Pollination in Berseem. Indian Journal Genetics and Plant Breeding, 26: 118-120.

Free, J.B. (1960). The behaviour of honeybees visiting the flowers of fruit trees. Journal of Animal Ecology, 29: 385-395.

Free, J.B. (1993). Insect pollination of crops. Academic Press, London, UK, pp. 684.

Hassanein, M.H. (1953). Studies on the effect of pollinating insects, especially the honeybee, on the seed yield of clover in Egypt. Bulletin de la Société Fouad Ier d' Entomologie, 37: 337-344.

Malaviya, D.R., Pandey, K.C., Roy, A.K. and Kaushal, P. (1999). Role of honey bees in seed setting of Egyptian clover. Crop Improvement, 26(2): 204-207.

McGregor, S.E. (1976). Insect pollination of cultivated crop 
plants. Agriculture Handbook Washington DC: United States Department of Agriculture, Agricultural Research Service, pp. 496.

Narayanan, E.S., Sharma, P.L., and Phadke, K.G. (1961). Studies on requirements of various crops for insect pollination insect pollinators of Egyptian clover (Triflolium alexandrinum) with particular reference to honey bees and their role in seed setting. Indian Bee Journal, 23(4/6): 23-30.

Pinzauti, M. and Martiniello, P. (2003). Guided pollination with solitary male insects for production of seed of fodder plants. Informatore Agrario, 59(24): 33-36.

Roy, A.K., Malaviya, D.R. and Kaushal, P. (2005). Pollination behaviour among different breeding populations of Egyptian clover. Plant Breeding, 124(2):171-175.

Sharma, S.K. and Singh, J.R. (2003). Pollination efficiency of Apis sp. on Egyptian clover (Trifolium alexandrinum L.) Forage Research, 28(4): 218-219.

Singh, J., Yadav. S. and Chhuneja, P.K. (2012). Quantitative and qualitative enhancement in Trifolium alexandrium seed production through pollination by Apis mellifera $\mathrm{L}$. Indian Journal of Applied Entomology, 26(1): 50-53. 